\title{
A ANÁLISE DA INTERLÍNGUA E A CARACTERIZAÇÃO DO PERFIL LINGUÍSTICO DO APRENDENTE COM BASE NAS TEORIAS DE AQUISIÇÃO DE UMA TERCEIRA LÍNGUA'
}

RESUMO: A perspetiva comum dos investigadores de L3 defende que os aprendentes plurilingues possuem um repertório linguístico-comunicativo mais rico (pelo menos quantitativamente) do que os aprendentes de uma L2 ${ }^{2}$. Admite, portanto, a possibilidade de transferência de conhecimentos da L1, mas também da L2, na apropriação de uma L3. A ativação e/ou bloqueio do conhecimento linguístico anterior (L1 e L2) na apropriação de uma L3 depende da conjugação de vários fatores, tais como as tipologias das línguas em questão e a proximidade interlinguística, a proficiência do falante, o efeito psicolinguístico da L2, a exposição à L2 e o uso frequente da mesma no contexto social e, porventura, ainda outros fatores que devem ser identificados e estudados.

Partindo deste pressuposto, acreditando que o processo de apropriação de uma L3/Ln é diferente do que uma L2, este artigo procura explicar de que modo é que os conhecimentos dos fatores condicionantes da apropriação de uma $\mathrm{L} 3 / \mathrm{Ln}$ podem ser potenciados e aplicados pelos professores/investigadores - nomeadamente nos instrumentos de recolha de dados, em particular no questionário - a fim de caracterizar o perfil dos aprendentes plurilingues.

Este tipo de abordagem reflexiva, teoricamente sustentável, parece extremamente positivo, tanto para a investigação como para o ensino. Por um lado, permite compreender desvios linguísticos causados pela influência

\footnotetext{
${ }^{1}$ Este trabalho é financiado por fundos nacionais através da FCT - Fundação para a Ciência e a Tecnologia, I.P. no âmbito do projeto "Línguas e Aprendizagens" - subprojecto: "Contacto linguístico e a apropriação de uma L3/Ln” (Ref. do projeto UID/ELT/04188/2013). Responsável: Abdelilah Suisse. Centro de Línguas, Literaturas e Culturas. Universidade de Aveiro.

${ }^{2}$ Neste artigo, a sigla L2 remete à primeira língua estrangeira aprendida depois da língua materna.
} 
interlinguística e, por outro, presta útil auxílio à ação didática, podendo construir-se esta sobre as competências linguísticas prévias dos alunos.

PALAVRAS-CHAVE: perfil linguístico plurilingue; interlíngua; aquisição de uma terceira língua; influência interlinguística em L3/Ln

ABSTRACT: The common perspective of L3 researchers argues that multilingual learners have a richer linguistic-communicative repertoire (at least quantitatively) than learners of a L2. Therefore, it allows the transfer of knowledge of a L1, but also of a L2, in the appropriation of a L3. The activation and / or blocking of the previous linguistic knowledge (L1 and L2) in the appropriation of a L3 depends on the complex conjugation of several linguistic, psycholinguistic and sociolinguistic factors.

Thus, believing that the process of appropriation of a L3 / Ln differs from the appropriation of a L2, this article tries to explain how the knowledge of these factors can be enhanced and applied by teachers / researchers, i.e. in data collection instruments, in particular in the questionnaire, in order to characterize the profile of multilingual learners.

KEYWORDS: multilingual linguistic profile; interlanguage; acquisition of a third language; cross-linguistic influence on L3 / Ln

\section{1 - Introdução}

Os estudos atuais sobre a aquisição de uma terceira língua (L3/ Ln) $)^{3}$ têm vindo a realçar um quadro teórico específico nesta área de investigação, defendendo a ideia de que os aprendentes plurilingues possuem um repertório linguístico-comunicativo mais rico (pelo menos a nível quantitativo) do que os aprendentes de uma segunda língua (L2). Considera-se atualmente que, no processo de apropriação de uma L3/Ln, existe sempre a possibilidade de transferir não apenas conhecimentos da primeira língua (L1), mas também da L2. A apropriação de uma L3/Ln, pelo envolvimento e contacto entre as várias línguas do repertório linguístico de base, afigura-se como um processo complexo, heterogéneo e dinâmico (Hufeisen 2000; Cenoz, Hufeisen \& Jessner 2001). De entre os fatores de cariz psicolinguístico e sociolinguístico (os mais desenvolvidos e referenciados na área dos estudos sobre L3), os mais importantes a ter em conta são: a tipologia e proximidade linguísticas, o efeito psicolinguístico da L2, o grau de proficiência linguística do falante em todas as

\footnotetext{
${ }^{3}$ Trevisiol \& Raste (2006: 1) explicam que «Le terme 'langue 3' (L3) renvoie d'une manière générale à la langue en cours d'acquisition au moment de l'observation. Il ne s'agit donc pas nécessairement de la deuxième langue étrangère et elle peut être précédée de plusieurs langues secondes (L2)».
} 
línguas do seu repertório, a exposição e o uso recente da L2 (nomeadamente Murphy 2003; Hammaberg 2006).

Assim, porque o processo de apropriação de uma L3/Ln é diferente do de uma L2, podemos repensar, discutir e propor métodos de investigação, de índole construtivista, que sejam adequados à caracterização do perfil linguístico dos aprendentes plurilingues, o que, por sua vez, deverá ajudar a melhor compreender a gestão do repertório linguístico-comunicativo na construção da interlíngua em L3/Ln.

Numa primeira fase deste artigo, e a fim de fornecer uma visão global sobre o assunto tratado, é feita uma revisão sobre os principais pressupostos teóricos e sobre alguns resultados empíricos relacionados com a interlíngua, nomeadamente sobre o papel da L1 - como processo e estratégia - na aprendizagem da L2. Seguidamente, são destacados os fatores psicolinguísticos e sociolinguísticos mais relevantes na mobilização de transferências da L1 e da L2 para a apropriação de uma L3/Ln. Por fim, articulando conceitos teóricos com a prática de investigação, é explicado como é que os conhecimentos dos fatores condicionantes da apropriação de uma L3/Ln podem ser potenciados e aplicados (quer por investigadores, quer por professores) nos instrumentos de recolha dos dados, particularmente no questionário, por forma a melhor se caracterizar o perfil linguístico dos alunos de LE (cf. Martins 2013). Este tipo de abordagem parece extremamente positivo para compreender melhor os desvios linguísticos produzidos na escrita, nomeadamente aqueles que são causados pela influência interlinguística.

2 - (Revendo) o papel da L1 na construção da interlíngua em L2: das teorias aos estudos empíricos

Os estudos da interlíngua surgiram no âmbito das investigações sobre o bilinguismo e a Análise do Erro (AE), por um lado, e, por outro, com o início da valorização do papel da L1 na aprendizagem de uma L2, demarcando-se estes estudos das tendências behavioristas da Análise Contrastiva, que caracterizaram a investigação nos anos cinquenta do século XX. Esta mudança de tendência de investigação, que valoriza a transferência linguística da L1 para a L2, estava relacionada com o surgimento, naquela época, de algumas teorias sociolinguísticas e psicolinguísticas, tais como a Interdependência Linguística (Cummins 1979) e as teorias cognitivas construtivistas da aprendizagem.

No âmbito deste debate, após a realização de estudos empíricos inspirados na teoria inatista de Chomsky, surgiram, quase de forma simultânea, estudos enquadrados na interlíngua (Selinker 1992 [1972]) e na AE de Corder (1992 [1971]), cujos objetivos eram, por um lado, compreender e construir uma teoria psicolinguística de aprendizagem da L2 e, por outro, melhorar o seu ensino. Nesta perspetiva, os erros, inclusive aqueles que eram causados pela L1, 
começaram a ser considerados como manifestação positiva e natural do processo de aprendizagem dos aprendentes, evidenciando estratégias individuais, através das quais os aprendentes testam hipóteses para produzir enunciados em L2. O foco estava sobre a influência da L1 na apropriação de uma L2, nomeadamente no que respeita à maior ou menor proximidade linguística entre as línguas em contacto (L1 e L2), e ao nível da proficiência dos aprendentes na L1.

Com efeito, Ringbom (1987) atribui uma importância fundamental à L1 na aprendizagem de uma L2, destacando as relações de semelhança entre a L1 e a L2. Para Ringbom, a L1 funciona como um cabide onde o aprendente pode pendurar nova informação, sobre o uso de conhecimentos já existentes, facilitando a aprendizagem da L2, sobretudo no caso de línguas próximas. Ringbom, contudo, refere que o efeito facilitador da L1 na compreensão da L2 varia consoante a perceção do aprendente e de como este possa estabelecer (eventuais) equivalências entre as duas línguas. Seguindo esta linha de raciocínio, Odlin (1989) considera a distância e o grau de semelhança linguística entre as línguas em contacto como decisivos para mobilizar a transferência da L1 para a L2: "Transfer is the influence resulting from similarities and differences between the target language and any other language that has been previously (and perhaps imperfectly) acquired" (Odlin 1989: 27). Todavia, este autor chama a atenção para o facto de a semelhança interlinguística poder tornar-se mais problemática do que determinadas diferenças, ou seja, o aprendente pode fazer uma "transferência cega" da L1 para L2, resultando numa transferência "negativa", isto é, não respeitadora das regras da nova língua em estudo.

Nesta perspetiva, Calvi (2004), refletindo sobre a aprendizagem de línguas afins (espanhol e italiano), alerta também para as correspondências estruturais e para a grande quantidade de coincidências lexicais, de tal modo que o aprendente tem a sensação de compreender a outra língua e de poder falá-la sem muito esforço. Ainda assim, à medida que o aprendente aprofunda os conteúdos da L2, surgem dificuldades insuspeitadas: as afinidades apresentam, frequentemente, divergências subtis.

Giacobbe (1992), no seu estudo sobre a aprendizagem do espanhol (L2) por falantes de francês (L1), refere a importância da L1 na aprendizagem da L2. Segundo este autor, o recurso ao conhecimento da L1 constitui uma construção hipotética, baseada na perceção das diferenças e semelhanças entre as línguas em contacto: "Le recours à la langue première dans la construction de l'interlangue et dans la production du discours doit être ainsi replacé, avec toute sa complexité, dans le cadre cognitif du processus d'acquisition" (Giacobbe 1992: 52).

À luz do exposto, constata-se que a transferência da L1 para a L2 se processa não apenas pelas semelhanças linguísticas entre as línguas, mas também pela distância subjetivamente perspetivada pelos aprendentes entre a L1 e L2, aquilo 
que Kellerman (1986) denomina de distância psicotipológica (psychotypology). Assim, este autor afirma que a transferência é restringida pela perceção que o aprendente tem da distância existente entre a L1 e a L2, e não pelas diferenças tipológicas "reais" (cf. Ringbom 1987). Desta forma, a psicotipologia (a distância percebida ou subjetiva) é o resultado do desenvolvimento da competência (meta) cognitiva e da consciência (meta)linguística do aprendente, que se tornou num dos fatores relevantes, como veremos mais adiante, no processo de apropriação de uma L3/Ln.

Em síntese, os estudos empíricos acima mencionados mostram que a interlíngua é um sistema de transição criado pelo aluno durante o processo de apropriação de uma L2, isto é, um produto linguístico, apresentando traços da L1, traços da L2 e outros especificamente idiossincráticos. A interlíngua de uma L2 reflete a dinâmica do processo de aprendizagem da L2 - através do qual o aprendente desempenha um papel ativo - e, ao mesmo tempo, explicita alguns fatores (psico)linguísticos que caracterizam o processo de aprendizagem da L2, conhecimento importante para os professores de LE.

No que diz respeito à recolha de dados, verifica-se que os investigadores se preocupavam, nos momentos da caracterização do perfil linguístico dos aprendentes, apenas em identificar a L1 adquirida e a proximidade desta com a língua-alvo, procedimentos esses, na nossa opinião, não adequados ao perfil dos aprendentes plurilingues que tiveram contacto com línguas estrangeiras. Estas línguas desempenham um papel relevante na apropriação de uma L3/Ln, como explicaremos seguidamente.

\section{3 - O papel da L1 e da L2 na construção da interlíngua na L3/Ln: da teoria aos estudos empíricos}

Tal como referimos na introdução, na apropriação de uma L3/Ln parece claro que as possibilidades de influência interlinguística são quantitativamente e qualitativamente maiores e variáveis, podendo ocorrer no sentido $\mathrm{L} 1 \rightarrow \mathrm{L} 3$ ou $\mathrm{L} 2 \rightarrow \mathrm{L} 3$, ou ainda no sentido L1 e L2 $\rightarrow$ L3/Ln. Além disso, o aprendente de L3 dispõe de uma experiência linguística prévia maior, que adquiriu no processo de aquisição e aprendizagem da L1 e da L2, capacidades metalinguísticas e criativas maiores, e competências de flexibilidade cognitiva (Hufeisen 2000) que lhe permitem, potencialmente, aplicar várias estratégias na nova aprendizagem.

Partindo deste princípio, defendemos que a caracterização do perfil linguístico deverá ter como guião principal as teorias de aquisição de uma L3, sobretudo considerando que, ao nível educativo, o plurilinguismo se tornou, há alguns anos, uma realidade bem comprovada.

Antes de expormos aspetos específicos das teorias de aquisição, nomeadamente os fatores e algumas variáveis que intervêm na apropriação de uma L3/Ln, importa referir que o seu impacto depende muito das características 
individuais cognitivas dos aprendentes, bem como do contexto sociolinguístico em que ocorre a aprendizagem.

Assim, ao referir alguns fatores (psico)linguísticos condicionantes no processo de aprendizagem de uma $\mathrm{L} 3 / \mathrm{Ln}$, destacamos a variável da tipologia e da proximidade linguísticas, o que pode ser observado em três situações: i) a proximidade com a origem das línguas; ii) as características comuns entre as línguas que não pertencem à mesma família linguística; iii) a distância subjetiva, ou "distância psicológica", percebida ou construída, pelo aprendente, entre as línguas anteriormente aprendidas - L1 e L2 - e a língua-alvo, a L3/ Ln. O aprendente pode, pois, estabelecer fontes de transferência entre estas línguas, que não são forçosamente consideradas similares, tal como refere De Angelis (2007: 22): "the distance that learners perceive to exist between languages that may, or may not, correspond to the distance that actually exists between them".

Relativamente ao fator da proficiência linguística, podemos inferir que se trata de uma condicionante que depende, para além das características individuais, da realidade sociolinguística e educação linguística do aprendente. É um fator que pode ser discutido, por sua vez, a vários níveis: a proficiência em L1 (sendo que esta, supostamente, é a língua adquirida); a proficiência na L2, isto é, quanto maior for a competência linguística do aprendente na L2, com mais facilidade ela é transferida, auxiliando a produção em L3, sobretudo se a L2 for aprendida e utilizada em contexto natural (Ringbom 2005) ou em contextos educativos, como o caso do francês que se ensina nos primeiros anos de escolaridade em Marrocos. O francês (L2) torna-se posteriormente uma referência, por exemplo, na aprendizagem do espanhol (L3) nos três anos do liceu (cf. Paniagua 2003). Há até autores que consideram que, quando o aprendente atinge o nível avançado em L3/Ln, se reduz a influência interlinguística procedente das línguas previamente apreendidas (Bardel \& Lindqvist 2007).

Em relação ao efeito psicolinguístico da L2, este não ocorre quando um aprendente monolingue aprende uma primeira língua não nativa e, por isso, esta variável constitui o ponto de divergência entre o processo que ocorre durante a apropriação de uma L2 e L3/Ln (Suisse 2016). Os investigadores reconhecem a existência de um modo cognitivo específico, "talk foreign" e/ou "foreign language mode" (De Angelis \& Selinker 2001; De Angelis 2005), que prevalece na gestão do repertório linguístico-comunicativo de um aprendente de uma L3/Ln, que, como já dissemos, não ocorre na apropriação de uma L2. Apesar de existirem semelhanças entre a L1 e L3, curiosamente, é a L2 que desempenha o papel designado de default supplier (Hammarberg 2006). Por outro lado, e conforme Sikogukira (1993), o efeito psicolinguístico de L2 pode ser proporcionado também noutras situações, nomeadamente pelo estilo 
de aprendizagem (materiais didáticos, metodologia de ensino, professor não nativo, etc.), bem como pelo ambiente onde se desenvolve o ensino da LE, que, por vezes, leva o aprendente a estabelecer, simultaneamente, relações de convergência entre a L2 e a L3/Ln e, ao mesmo tempo, de divergência entre a L2 e a L1.

Para alguns investigadores, o efeito da exposição e uso recente de uma L2 constitui-se como o fator mais influente na transferência linguística, independentemente da proximidade tipológica entre a L1 e a L3 (Shanon 1991). Esta hipótese foca-se sobretudo na ideia de atualidade: "how recently a language was last used" (De Angelis 2007: 35). A exposição e o uso recente de uma L2 poderão estar relacionadas com a motivação instrumental que o aprendente tem em relação a uma determinada LE. Neste último caso, o aprendente vai tendo um filtro afetivo baixo no uso de uma LE, querendo isto dizer que consegue usá-la com maior facilidade, maior eficácia (Krashen 1992) e com grande motivação científica por ser, por exemplo, a língua de especialização em curso superior universitário (cf. Suisse 2016). Como consequência disso, o uso frequente da L2 acaba por prevalecer na memória de longo prazo (Izquierdo 2002; Martins 2012) e, por isso, o aprendente terá mais possibilidades de a transferir, comparativamente a outras menos utilizadas (De Bot 2004). De acordo com a nossa experiência de professor de árabe (L3/Ln), no contexto universitário português, verificamos que isto acontece quando os alunos realizam, antes da nossa aula, trabalhos ou testes em outras línguas estrangeiras do curso (ex. inglês, francês, espanhol ou alemão), pois facilmente estas línguas são transferidas, ao nível de estruturas morfossintáticas, para o árabe, mesmo quando os próprios alunos têm consciência de que a transferência do português para o árabe poderá resultar positiva. Além disso, em alguns contextos educativos, a ordem da aprendizagem de uma LE - ou seja, a última língua aprendida - pode influenciar a que vai ser aprendida a seguir (Bono 2010).

Assim, apesar de termos apresentado de forma separada cada um dos fatores, na verdade eles são interdependentes e interagem entre si, numa relação dinâmica e complexa, levando o aprendente a ativar e transferir (ou não) uma língua do repertório linguístico-comunicativo no processo de aprendizagem de uma L3, como se vai comprovando em estudos realizados em contextos educativos africanos e europeus. Para este artigo, selecionamos estudos realizados sobre várias línguas de L3/Ln (inglês, francês e português), aprendidas por falantes nativos de línguas europeias e não europeias.

Bentahila (1982) foi um dos primeiros autores a trabalhar sobre a aprendizagem de L3 no contexto educativo africano, particularmente com aprendentes de inglês no norte de África. Este autor analisa, no seu estudo, a transferência linguística na aprendizagem do inglês (L3) em alunos do ensino secundário do Magrebe (marroquinos e argelinos), cujo repertório linguístico- 
-comunicativo é constituído pelo árabe (L1) e pelo francês (L2), utilizando um grupo de controlo, constituído por alunos iraquianos e kuwaitianos que tinham o árabe como L1 e estavam a aprender inglês (L2).

Bentahila chega à conclusão de que os alunos marroquinos e argelinos aprendentes de inglês (L3) fazem um uso "excessivo" de transferências do francês (L2), devido à perceção da proximidade linguística entre ambas as línguas, em detrimento do árabe (L1). No entanto, em algumas situações, a transferência da L1 pode resultar positiva, como aconteceu com o grupo do Médio Oriente. Neste caso, a perceção do estatuto do francês como LE e o efeito psicolinguístico desta língua inibe a ativação da L1.

Ahukanna, Lundo \& Gentille (1981), no seu estudo sobre alunos nigerianos de francês (L3) que têm o igbo como L1 e o inglês como L2, ressaltam que o efeito psicolinguístico da L2 e a proficiência na L1 são fatores principais para a compreensão da interferência (termo usado pelos autores) linguística que ocorre na aprendizagem da L3. Este estudo desenvolveu-se na Nigéria, onde o inglês é a língua oficial utilizada no ensino, no comércio e nos média, enquanto o igbo (L1) é adquirido no contexto familiar. $O$ estudo comprova que a proficiência na língua igbo (L1) e o efeito psicolinguístico da LE (inglês) podem explicar a presença de traços linguísticos destas línguas na produção escrita dos aprendentes do francês (L3). Estes desvios verificam-se, ora de forma separada, ora de forma simultânea, neste último caso, apresentando estruturas morfossintáticas híbridas em francês (L3), com a influência do igbo (L1) e do inglês (L2).

O estudo de Kabore (1983), realizado também no contexto africano, confirma igualmente o efeito psicolinguístico da L2 no processo de aprendizagem de uma L3. Este autor debruça-se sobre a possibilidade da transferência sintática (L1 ou L2) no processo de apropriação de uma L3. Os participantes nesta investigação são alunos falantes de uma língua da África Ocidental, o moore (L1), de francês (L2) e estão a aprender o inglês (L3). Embora, segundo o autor, o moore (L1) e o inglês (L3) sejam línguas mais próximas fonética e sintaticamente, os alunos transferiram muitas estruturas do francês (L2), o que foi interpretado como confirmação da hipótese de que, na apropriação da L3, o fenómeno da transferência nem sempre surge com base nas similaridades linguísticas, e o efeito psicolinguístico da LE é muito relevante nesse contexto.

Suisse (2011) analisa as produções escritas de 21 alunos marroquinos do $2 .^{\circ}$ ano do Curso de PLE do Leitorado do Instituto Camões da Universidade de Fez, em Marrocos, que apresentam dois perfis diferentes. O Grupo 1 (G1): árabe padrão e a variante dialetal (L1), francês (LE1), espanhol (LE2) e português (LE3); o Grupo 2 (G2): árabe padrão e a variante dialetal (L1), francês (LE1), inglês (LE2) e português (LE3). O estudo pretende compreender como funciona o repertório linguístico-comunicativo dos alunos universitários marroquinos no processo da apropriação do português (LE3). 
Verifica-se que, na interlíngua do G1, prevalecem as transferências lexicais do espanhol, língua mais próxima do português, sendo também a mais utilizada no contexto académico, bloqueando, ao mesmo tempo, as do francês (LE1). Em relação ao G2, desativando o inglês (LE2), acabam por transferir para o português mais traços linguísticos do francês (LE1), língua que estudavam no curso em que estavam inscritos. Apesar desta diferença na gestão do repertório linguístico-comunicativo, ambos os grupos, ainda que em menor grau em relação às outras línguas, transferem também do árabe padrão (L1) e do dialeto marroquino para o português (LE3), particularmente aspetos relacionados com a concordância de género e expressões idiomáticas. Em conclusão, este estudo demonstra que a proximidade linguística, a proficiência, a exposição e o uso recente do espanhol (LE2), no caso do G1, e do francês (LE1), no caso do G2, são os principais fatores que fazem com que os aprendentes marroquinos selecionem e transfiram em grande quantidade estas línguas românicas para o português (LE3).

No contexto educativo europeu, destacamos o estudo de Dewaele (1998), que estuda os níveis de ativação das línguas do repertório linguístico-comunicativo dos aprendentes de francês (L2/L3). Os resultados encontrados atestam uma influência interlinguística visível na produção de itens lexicais em ambos os grupos analisados. O primeiro grupo, constituído por falantes de francês L2, parece ativar com mais frequência os conhecimentos linguísticos de neerlandês (L1), ao passo que o segundo grupo, de falantes de francês L3, utiliza sobretudo elementos linguísticos relacionados com o inglês (L2). Como explica o próprio autor, "the level of activation is partially blocked. It appears that the LI is not necessarily always the dominant active language and that access to its lemmas could accordingly be limited" (Dewaele 1998: 488). Assim, parece existir um bloqueio que impede o uso da L1 na produção de itens lexicais em L3 porque os aprendentes já conhecem uma L2. O estudo de Dewaele (1998) aponta, assim, como fatores possíveis para compreender as influências linguísticas nos sujeitos trilingues, tanto o efeito do inglês (L2) como, eventualmente, a tipologia linguística entre o léxico desta língua e o do francês (L3).

Em outro estudo, Flynn, Foley \& Vinnitskaya (2004) debruçam-se sobre a aquisição das frases subordinadas em inglês (L3) por falantes de cazaque (L1), tendo o russo como L2. Os autores explicam que o inglês e o russo são línguas "cabeça à esquerda" (as frases subordinadas completivas aparecem à direita do nome), enquanto o cazaque, como todas as línguas altaicas, é uma língua de "cabeça à direita" (as subordinadas completivas aparecem à esquerda do nome). Dada a proximidade entre a L2 e a L3, os autores presumem que os aprendentes devem usar a sua experiência linguística, especialmente do russo (L2), na produção das subordinadas em inglês (L3). Os resultados obtidos confirmam esta hipótese, o que leva os autores a concluir: "language learning is cumulative, 
all languages known can potentially influence the development of subsequent learning" (Flynn, Foley \& Vinnitskaya 2004: 5). Este estudo propõe ainda o modelo "cumulative-enhancement", que defende que uma L2 só se torna fonte de transferência quando a estrutura da L3 não está presente na L1.

Leung (2007), na mesma linha investigativa de Flynn, Foley \& Vinnitskaya (2004), examina a transferência sintática no sintagma nominal, explicando que os aprendentes de francês (L3), tendo o cantonês como L1 e o inglês como L2, produzem uma transferência completa das categorias funcionais pertencentes ao inglês (L2), nomeadamente a presença do artigo definido, categoria gramatical que não existe no cantonês. A omissão e/ou a inibição do artigo na interlíngua de um grupo de controlo de aprendentes de inglês (L2) que têm o cantonês como L1 leva o autor a afirmar que, no caso de o aprendente conhecer uma L2 que partilhe as mesmas propriedades com uma L3, esta última poderá ser mais fácil de aprender.

Noutro estudo, Pinto \& Carvalhosa (2012) analisam as produções escritas de 37 alunos universitários de português (L3/L4), falantes de sérvio plurilingues, pois todos já tinham estudado, ou estudavam no momento da recolha dos dados, outras línguas (L2) (espanhol, italiano, francês, inglês e russo). O estudo pretendia identificar as influências das línguas previamente aprendidas ao nível lexical e sintático, bem como os fatores (proficiência em L2, tipologia linguística e uso recente da L2) que causam as referidas influências na interlíngua de português (L3/L4). Os resultados mostram que os alunos sérvios desativam, em grau maior, a L1 em detrimento da língua que estão a usar nos seus cursos, tais como o espanhol ou o francês, que são as línguas às quais os sujeitos estão mais expostos e que são, ao mesmo tempo, tipologicamente mais próximas do português.

O estudo de Pinto (2015) procura identificar os fatores que facilitam a transferência do léxico de português L3 na produção escrita de 62 alunos, falantes de inglês (L1), no contexto universitário português e que, segundo o autor, têm bons conhecimentos de espanhol e de francês (L2). O estudo conclui que a proximidade entre a língua-alvo, o português (L3), e as línguas não maternas, o espanhol e o francês (L2), condicionaram as transferências ao nível lexical. O autor refere ainda que a exposição a outras línguas estrangeiras românicas (espanhol e francês) e a proficiência maior que os aprendentes possuem numa destas línguas estrangeiras têm uma influência considerável na apropriação do português L3. Paralelamente a este processo de transferência, os aprendentes desativam o inglês (L1), que é uma língua germânica, mais distante do português. Neste estudo, confirma-se a ideia de que os alunos plurilingues conseguem ter a consciência da distância tipológica entre as línguas em contacto, tal como se verifica entre o inglês e o português. 
Em suma, os estudos apresentados comprovam que as possibilidades de influência interlinguística da L1 ou da L2, ou de ambas, na apropriação da L3/Ln podem ser explicadas pela conjugação hipotética e complexa de vários fatores: proximidade e tipologia linguísticas, proficiência linguística, exposição e uso recente da L2 e o efeito psicolinguístico da L2, tal como salienta Hammaberg (2006: 15-16) no seguinte excerto:

il est loin d'être évident de définir l'intensité de l'influence relative des différents facteurs pour un apprenant donné dans une situation donnée. Un facteur peut entraîner une différenciation importante ou faible entre les langues pour un apprenant et ainsi être plus ou moins décisif. Le poids relatif des différents facteurs per se est jusqu’à présent incertain.

Face a esta complexidade que caracteriza o processo de aprendizagem de uma L3/Ln, torna-se imperativo, por parte do investigador e do professor de LE, o conhecimento exaustivo dos principais fatores que intervêm no processo de apropriação de uma L3/Ln, reforçado, naturalmente, com o conhecimento dos estudos empíricos, realizados sobre várias línguas e em contextos diferentes. Estes conhecimentos permitem a investigadores e docentes possuir uma sensibilidade teórica (Theoretical Sensitivity) (Strauss 1978) e prática para construir o instrumento de recolha de dados, nomeadamente o questionário, adequado para caracterizar o perfil linguístico do aprendente de línguas plurilingue (cf. Suisse 2016). Posteriormente, deverão conseguir compreender melhor como se constrói a interlíngua, decifrando as transferências interlinguísticas em L3/Ln.

\section{4 - A caracterização do perfil linguístico dos aprendentes plurilingues: uma proposta de recolha de dados}

Antes de iniciar a construção do perfil linguístico dos aprendentes que participam num determinado estudo, convém ao investigador recolher dados acerca do contexto educativo onde decorre o seu estudo, aquilo que Castellotti \& Moore (2002: 22) designa de "micro-contextes" (verificamos que a maioria dos estudos sobre aprendentes de L3 se realiza em contextos universitários, como no caso da língua portuguesa), sem descurar o sistema educativo do país e as políticas linguísticas adotadas (Blanchet \& Asselah-Rahal 2008). Esta fase de investigação poderá necessitar de uma recolha adicional de documentos credíveis de várias fontes oficiais que esclarecem o estatuto das línguas, ao nível constitucional e ao nível escolar. Desta recolha, o investigador poderá formar uma ideia-esboço acerca da cronologia de aprendizagem das línguas no âmbito escolar.

Cumprida esta fase preliminar, o investigador/professor deve avaliar as variáveis em relação às línguas em contacto, sendo imperativo identificar as línguas que formam o repertório linguístico-comunicativo dos aprendentes. Se, por exemplo, o conhecimento de línguas por parte do aprendente se limita às 
línguas românicas ou, por outro lado, se conjuga estas com outras germânicas ou semitas, etc. Importa sublinhar que, no mesmo contexto educativo, podemos encontrar vários perfis diferentes. A partir da informação sobre o reportório, o investigador poderá avaliar a proximidade entre as línguas que o aprendente conhece e sobre o (eventual) efeito psicolinguístico da LE que, como já destacámos, muitas vezes é considerado como fator a ter em consideração para explicar os desvios da interlíngua em L3.

Com o objetivo de identificar a cronologia de aprendizagem das línguas e o grau de exposição e uso recente destas em relação às línguas do repertório, deve ser solicitada, no questionário, outra informação: o número de anos ou meses de aprendizagem das línguas. A ideia é identificar, por exemplo, a cronologia de aprendizagem das línguas e verificar se ocorreram em contexto formal ou informal. Em relação ao uso recente das línguas, é importante saber quais as línguas aprendidas ao mesmo tempo que a língua alvo, a L3/Ln. Como já foi mencionado, em alguns estudos empíricos é frequente que se estude uma L3/ Ln em cursos livres, já numa fase avançada da formação académica, podendo o estudo decorrer em simultâneo com o estudo de outra língua, por exemplo num curso de licenciatura, como ocorre com o português no contexto universitário marroquino. Os alunos deste país frequentam as aulas de português após terem estudado outros idiomas estrangeiros, tais como o francês (LE1), espanhol ou inglês (LE2) (cf. Suisse 2011; Pinto 2012). Este tipo de dados fornece informação útil para a avaliação do uso recente de uma LE. Por exemplo, um aluno que estuda numa licenciatura de Estudos Franceses ou Hispânicos, ou ainda de uma outra língua, terá mais contacto com disciplinas linguísticas ou filológicas de âmbito científico (Estudos Literários, Linguística, etc.)

Por outro lado, apesar de ser consensual entre os investigadores o reconhecimento da importância do fator proficiência linguística de uma das línguas do repertório na transferência de L1 e/ou de L2 para L3/Ln, recolher dados acerca desse fator continua a ser discutível, sobretudo em relação à(s) L2(s), já que a L1 é a língua adquirida e a língua de instrução, provavelmente mais dominada ao nível do conhecimento implícito e explícito pelos aprendentes de uma L3/Ln. Assim, na impossibilidade de realizar testes de proficiência (pela natureza do estudo e/ou falta de tempo) nas línguas que o aprendente conhece, é viável, como alternativa, solicitar a autoavaliação dos inquiridos (cf. Cenoz 2003; De Angelis 2005; Bardel 2006; Suisse 2016) usando uma escala de avaliação qualitativa e/ou quantitativa conhecida pelos sujeitos. Para compreender ainda melhor a autoavaliação dos sujeitos, é recomendável realizar uma entrevista focus group (cf. Suisse 2016).

Para finalizar, podemos afirmar que os procedimentos de recolha de dados para a caracterização do perfil linguístico são condicionados pelos objetivos e questões levantados pela investigação e, por isso, a proposta aqui apresentada 
deve ser flexível tendo em conta o objetivo de cada investigação. Os dados a recolher poderão, naturalmente, ser mais precisos sempre que for necessária informação específica relevante para a investigação.

\section{5 - Considerações finais}

Começámos este artigo apontando as diferenças entre o processo de aprendizagem da L2 e da L3/Ln para repensar a forma como se caracteriza o perfil linguístico dos aprendentes plurilingues. A partir desta consideração, as reflexões aqui apresentadas pretenderam articular aspetos teóricos, no âmbito das teorias de aquisição, experimentados por alguns estudos empíricos, abrindo caminhos, na medida do possível, ao conhecimento do mundo do aprendente plurilingue, que costuma apresentar variáveis e especificidades individuais complexas.

Assim, num âmbito de aprendizagem das LE, defendemos a ideia de que a caracterização do perfil linguístico não pode ser feita sem um referencial teórico sustentável, porque constitui o primeiro momento de interação com os dados obtidos, cujos resultados poderão ser decisivos para identificar variáveis potencialmente relevantes em fases posteriores da investigação. Efetivamente, muitas vezes a caracterização detalhada do perfil linguístico dos aprendentes faculta ao investigador informações sobre as variáveis específicas do grupo em estudo e, conseguintemente, o investigador poderá privilegiar (mesmo sem ter sido objetivo inicial) um estudo comparativo da interlíngua produzida no processo da apropriação de uma $\mathrm{L} 3 / \mathrm{Ln}$, garantindo maior profundidade e rigor à interpretação dos dados.

Tal como mencionámos em trabalhos anteriores (Suisse 2016; Suisse \& Andrade 2018), a caracterização do perfil linguístico dos alunos plurilingues é igualmente positiva na construção e desenvolvimento de competências didáticas dos professores, nomeadamente para aqueles que pretendem focar o seu ensino nas competências prévias dos alunos, potenciando-as numa abordagem plural, construtivista e integrada, fundamentada na ideia do plurilinguismo como "tremplin d'apprentissage" (Castelloti \& Moore 2002: 20).

\section{REFERÊNCIAS}

Ahukanna, J. G. W.; Lundi, N. J.; Gentille, L.-R. 1981. Inter-and-intra-lingual interference effects in learning a third langue. The Modern Language Journal. 65(3): 281-287.

Bardel, C. 2006. La connaissance d'une langue étrangère romane favorise-telle l'acquisition d'une autre langue romane? Influences translinguistiques dans la syntaxe en L3. AILE. 24: 149-180. 
Bardel, C.; Lindqvist, C. 2007. The role of proficiency and psychotypology in lexical cross-linguistic influence. A study of a multilingual learner of Italian L3. In: M. Chini; P. Desideri; M. E. Favilla; G. Pallotti (Eds). Atti del VI Congresso di Studi dell'Associazione Italiana di Linguistica Applicata. Perugia: Guerra Editore, 123-145.

Bentahila, A. 1982. The influence of L2 on the learning of L3. In: A. Benhallam (Ed.). Second Conference of MATE. Fes: University Sidi Mohamed Ben Abdellah, 13-27.

Blanchet, P.; Asselah-Rahal, S. (2008). Pourquoi s'interroger sur les contextes en didactique des langues? In: P. Blanchet; D. Moore; S. Asselah-Rahal (Dirs). Perspectives pour une didactique des langues contextualisée. Paris: Éditions des archives contemporaines, 9-10.

Bono, M. 2010. L'influence des langues non maternelles dans l'acquisition du SN en espagnol L3. Langage, Interaction et Acquisition. 1(2): 251-275.

Calvi, M. V. 2004. Aprendizaje de lenguas afines: español e italiano. Revista RedELE, $\mathbf{1}$.

Castellotti, V.; Moore, D. 2002. Représentations sociales des langues et enseignements. Guide pour l'élaboration des politiques linguistiques éducatives en Europe - De la diversité linguistique à l'éducation plurilingue. Strasbourg: Conseil de l'Europe.

Cenoz, J. 2003. The additive effect of bilingualism on third language acquisition: a review. The International Journal of Bilingualism. 7(1): 71-87.

Cenoz, J.; Hufeisen, B.; Jessner, U. (Eds.). 2001. Cross-linguistic influence in third language acquisition: psycholinguistic perspectives. Clevedon: Multilingual Matters.

Corder, S. P. 1992 [1971]. La importancia de los errores del que aprende una lengua segunda. In: J. M. Liceras. La adquisición de las lenguas extranjeras. Madrid: Visor, 31-40.

Cummins, J. 1979. Linguistic Interdependence and the Educational Development of Bilingual Children. Review of Educational Research. 49: 222251.

De Angelis, G. 2005. Interlanguage transfer and function words. Language Learning. 55(3): 379-414.

De Angelis, G. 2007. Third or additional language acquisition. Clevedon: Multilingual Matters.

De Angelis, G.; Selinker, L. 2001. Interlanguage transfer in competing linguistic systems in the multilingual mind. In: J. Cenoz; B. Hufeisen; U. Jessner (Eds.). Cross-linguistic Influence in third language acquisition: psycholinguistic perspectives. Clevedon: Multilingual Matters, 42-58.

De Bot, K. 2004. The multilingual lexicon: modelling selection and control. International Journal of Multilingualism. 1(1): 17-30. 
Dewaele, J.-M. (1998). Lexical inventions: french interlanguage as L2 versus L3. Applied Linguistics. 19(4): 471-490.

Flynn, S.; Foley, C.; Vinnitskaya, I. 2004. The Cumulative-Enhancement Model for Language Acquisition: Comparing Adults' and Children's Patterns of Development in First, Second and Third Language Acquisition of Relative Clauses. International Journal of Multilingualism. 1(1): 3-16.

Giacobbe, J. 1992. Acquisition d'une langue étrangère: cognition et interaction. Paris: CNRS Editions.

Hammaberg, B. 2006. Activation de L1 et L2 lors de la production orale en L3. Étude comparative de deux cas. AILE. 24: 45-74.

Hufeisen, B. 2000. A European perspective: tertiary languages with a focus on German as L3. In: J. W. Rosenthal (Ed.). Handbook of undergraduate second language education. New Jersey: Lawrence Erlbaum Associates, 209-229.

Izquierdo, I. 2002. Memória. Porto Alegre: Artmed.

Kabore, M. 1983. Syntactic transfer in third language learning: pedagogical implications. $\mathrm{PhD}$ thesis. Austin: University of Texas.

Kellerman, E. 1986. An eye for an eye: Crosslinguistic constraints on the development of the L2 Lexicon. In: E. Kellerman; M. Sharwood Smith (Eds.). Crosslinguistic Influence in Second Language Acquisition. New York, NY: Pergamon Press.

Krashen, S. 1992. El Modelo del monitor y la actuación de los adultos en L2. In: J. M. Liceras (Trad.). La adquisición de las lenguas extranjeras. Madrid: Visor, 143-151.

Leung, Y-KI. 2007. Second language (L2) English and third language (L3) French article acquisition by native speakers of Cantonese. International Journal of Multilingualism. 42: 117-149.

Martins, C. 2012. O papel diferenciado de subsistemas de memória de longo prazo nos processos de aquisição e de aprendizagem de uma L2. O modelo declarativo/procedimental e as suas consequências para o ensino de línguas não maternas. In: J. N. C. Cardoso (Ed.). A Linguagem na Pólis. Coimbra: Centro de Estudos Clássicos e Humanísticos, 1-18.

Martins, C. 2013. O Corpus de Produções Escritas de Aprendentes de PL2 (CELGA). Caracterização e desenvolvimento de uma infraestrutura de investigação. In: R. Bizarro; M. A. Moreira; C. Flores (Orgs.). Português Língua Não Materna: investigação e ensino. Lisboa: Lidel, 69-79.

Murphy, S. 2003. Second language transfer during third language acquisition. Working Papers. TESOL \& Applied Linguistics. 3(1): 1-21.

Odlin, T. 1989. Language Transfer, Cross-linguistic Influence in Language Learning. Cambridge: Cambridge University Press.

Paniagua, L. R. (2003). Fenómeno de transferência en aprendices árabes de E/LE. Forma. SGEL: Madrid. 5: 9-34. 
Pinto, J. 2012. A aquisição de português LE por alunos marroquinos: dificuldades interlinguísticas. In: A. G. Benito; I. Ogando (Eds.). Actas del II Congreso Internacional de la Sociedad Extremeña de Estudios Portugueses y la Lusofonía. Cáceres: SEEPLU/CILEM/LEPOLL, 217-239.

Pinto, J. 2015. O papel da L1 e da L2 na aquisição lexical de português L3. Revista liLETRAd. 1: 299-310.

Pinto, M. G.; Carvalhosa. A. 2012. Cross-Linguistic influence in third language acquisition. The case of Portuguese as a third language in Serbian Students. In: D. Gabrys-Barker (Ed.). Cross-linguistic Influences in Multilingual Language Acquisition, Second Language Learning and Teaching. Berlin: Springer-Verlag, 169-183.

Ringbom, H. 1987. The Role of the first language in foreign language learning. Clevedon: Multilingual Matters.

Ringbom, H. 2005. L2 - Transfer in Third language acquisition. In: B. Hufeisein; F. Robert (Eds.). Introdutory Reading in L3. Tubingen: Stauffenberg Velag, 71-82.

Selinker, L. 1992[1972]. La interlengua. In: J. M. Liceras. La adquisición de las lenguas extranjeras. Madrid: Visor, 79-101.

Shanon, B. 1991. Faculty language selection in polyglots. Language and cognitive processes. 6(4): 339-350.

Sikogukira, M. 1993. Influence of languages other than the L1 on a foreign language: a case of transfer from L2 to L3. Edinburgh working papers in Applied Linguistics. 4: 110-132.

Strauss, A. L. 1978. Negotiations. Varieties, contexts, processes, and social order. San Francisco: Jossey-Bass.

Suisse, A. 2011. Os desafios do ensino-aprendizagem do português como LE3 no contexto universitário marroquino. MAGRIBERIA. 4: 169-184.

Suisse, A. 2016. Transferência linguística na aprendizagem do português como terceira língua estrangeira por estudantes universitários marroquinos. Tese de Doutoramento em Educação - Ramo Didática e Desenvolvimento Curricular. Universidade de Aveiro.

Suisse, A.; Andrade, A. I. 2018. Fatores relevantes na apropriação de uma terceira língua: importância para o conhecimento do professor de língua estrangeira. As línguas estrangeiras no ensino superior: balanço, estratégias e desafios futuros. APROLÍNGUAS/FLUP e-DITA, 9-30.

Trévisiol, T.; Rast, R. (Eds.). 2006. Présentation. AILE. 24: 3-11. 